\title{
The color of geologic data: Using color computer images to display data
}

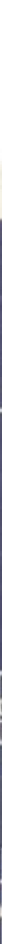


Earth science information has been associated for a long time with colored illustrations, which have persisted in this field even though other sciences have largely restricted the use of color in their publications. Indeed, color is being used increasingly today in the earth sciences, whether in publications, in computer applications, or in data collection.

Color-coded visualizations of data on computers allow the researcher to experiment visually and directly, and this is having a dramatic effect on traditional methods of scientific communication. For example, the increased use of printed color graphics in earth science publications and animated color images at meetings reflects a change in the use of color.

Researchers who experiment with color-data representation are concerned about the high cost of color publishing and about the most effective use of color. But beyond these concerns lie the responsibilities of conference organizers, publishers, and librarians. Because color graphics often are photocopied and microfilmed in black and white, these supporting groups are interested in seeing that color copy not only is well communicated but is distributed to the users in color and is preserved in color, all challenges that need to be met. (Ed.)
The drawing is a key to some of the elements used in highlighting part of Lamont-Doherty Geological Observatory's (L-DGO's) 40-year history, as shown in one-half of a timeline collage used on the cover of its 40th anniversary yearbook (Lamont-Doherty Geological Observatory of Columbia University/ 1989). Cover designed by Janet Kroboth-Weber.

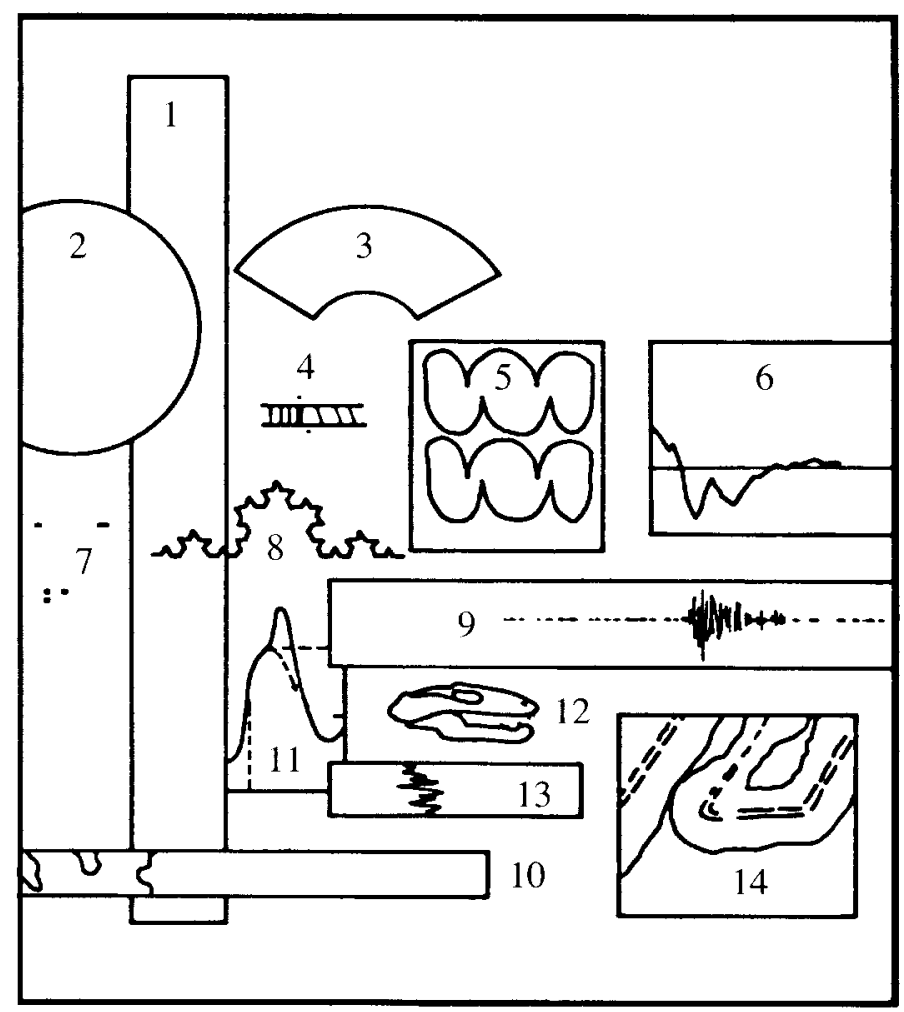

(1) Multi Channel Seismic (MCS) studies now use color in reflection records. This part of a record shows colors that are coded to measures of lateral coherence of relective horizons.

(2) The wind pattern of the Northern Hemisphere computed by a model that examines the influence of mountains versus no mountains on long-term global climate changes.

(3) The Scotia Arc and floor of the Weddell Sea as imaged by variations in the gravitational pull of the Earth over the ocean. These variations, which are mainly due to ocean floor topography, were mapped by an orbiting satellite.

(4) The growth rings in old trees contain a lot of history. These rings, shown in cross section, are from a tree in California, USA, and reveal a strong disruption in growth after an earthquake in 1813 .

(5) A global map of $\mathrm{CO}$, exchange with ocean surface waters. Blue shows zones where $\mathrm{CO}_{2}$ is absorbed and red where $\mathrm{CO}_{2}$ vents to the atmosphere.

(6) A theoretical model that predicts climate variation due to $\mathrm{El}$ Niño events ( $x$ 's) in comparison to actual observations (solid line).

(7) These points are taken from plotted data from L-DGO's mass spectrometer and show isotopic composition of strontium in volcanic rocks in the Mariana Arc.

(8) An illustration of fractal geometry, a powerful new tool for understanding ocean floor topography.

(9) This seismogram of an earthquake (magnitude 6) in Saguenay, Quebec, Canada, shows measurement of acceleration as recorded at one station of Lamont's digital strong motion network. L-DGO is a core facility for the National Center for Earthquake Engineering Research (NCEER).

(10) A section of a deep sea core from the L-DGO repository L-DGO maintains the largest collection of deep sea core in the world.

(11) The long-term climate of the Earth is controlled by variation in its orbit (Milankovitch cycles). The curve shows future climates with and without greenhouse warming.

(12) Mammallike reptile reconstructed from a fossil find in the Richmond, Virginia, USA, basin.

(13) The mineralogy of rocks drilled in Cajon Pass, California, USA, on the San Andreas fault as measured by downhole logs.

(14) The bathymetry over the crest of the East Pacific Rise obtained by the SeaMARCII System. The heavy black line shows the ship track. The cooler colors shown deeper depths. 
A dramatic change is taking place in earth science information. Unlike revolutionary changes in theory that are discernible only through careful reading of the great gray blur of journal articles, the new changes catch the eye immediately. The halls of our research institutions suddenly display arrays of brightly colored representations of data. Increasingly, researchers work at color computer monitors and manipulate color-coded data sets in order to analyze data better. Assessing and affording color printers become a new concern. Earth science conferences are faced both with the problem of making available projection equipment for computers and with the necessity of providing video equipment to present animated color images. And almost as fast as color has been adopted as a tool in research, earth science journals have begun to sport color pages, which bring with them an attendant struggle to afford the costs.

In the past year, even as the large, colored, folded maps seemed to ebb in volume in the journals, researchers began to produce new kinds of computer-generated color images in many areas of the earth sciences. Discussions erupted over the importance of these techniques, and some researchers heatedly suggested that the increasing use of color was a fad or the "selling of science." Meanwhile, research group after research group turned to the new techniques. Scientists also began to ask for research on the most effective use of color.

The use of color in the earth sciences is not a new technique. The literature of the earth sciences is characterized by the inclusion of colored maps and charts, frequently oversized. The first volume of the Quarterly Journal of the Geological Society of London in 1845 included a colored map with the article by David Walker, "On the Newer Coal Formation of the Eastern Part of Nova Scotia" (Walker, 1845). And in a study several years ago, I verified the high percentage of geology serials and monographs that contain colored materials (Klimley, 1982).

The use of costly color graphics has persisted in earth science journals over the years. long after other sciences have largely restricted publication to black-and-white illustrations. This raises the interesting question of what are the unique benefits that color brings to the earth sciences? This question, asked in light of traditional practices, may also give us insight into the increasing use of color today.

Pattern recognition is an important factor in the use of color. Logically, color is an aid in understanding the complex geologic maps and cross sections that are used to represent the geology of an area. I hoped that an examination of the literature of color science or psychology might reveal studies relating pattern recognition to color coding. I also hoped that a general theory of color use might exist that would help earth scientists improve the use of color in their new applications.

Unfortunately, the literature of psychology and ergonomics is not enlightening as to the intellectual or perceptual benefit of color representation of data. Psychologists have done research on color coding as an aid to what psychologists refer to as visual search, that is, locating symbols in an image (Carter, 1982). Much of this work has been done for the military in order to improve target recognition by fighter pilots. In addition, cartographic literature has some comparisons between coding by texture or symbol and color coding (Phillips and Noyes, 1980). Color coding has a slight quantitative advantage over texture coding. And further, computer scientists are doing some research into color perception as it relates to the use of color monitors (Weert. 1988).

In the end, however, the data on color perception seem fragmentary, and no overall theory for improvement of representation of color seems to have emerged from the research. Perhaps because of the very nature of designing tests of human abilities, the scope of the research appears to be limited to target recognition rather than encompassing the more complex pattern recognition that is necessary in analysis of a geologic map. One researcher suggests that we need guidelines rather than "rules of thumb" in the use of color in computer displays (Weert, 1988).

The only area of scientific thought that provides a larger framework for understanding the increasing use of color today is the study known as "visualization." Visualization is a specialized area of psychology and a rapidly growing area of computer science. The ability to visualize scientific data graphically is being understood gradually as a major advance in scientific instrumentation and is characterized by some as the second computer revolution. Although not widely distributed, a study of the workshop on Visualization in Scientific Computing, sponsored in 1987 by the U.S. National Science Foundation, recommended heightened application of graphics and image processing as the method for dealing with the gigabytes of data now collected daily from satellites, earth monitoring stations, and ships (McCormick and others, 1987). Color-data representation is just one component of visualization that includes complex computer modeling. Molecular structure, climate systems, and geologic formations all may be visualized graphically by using known data that are then manipulated by altering data variables.

The concept of visualization seems to give a good description of the changes taking place - and perhaps even of the historic use of color. After all, what does a geologic map represent but a visualization of the Earth's structures? The use of color helped so much to differentiate the complex patterns represented on maps and diagrams that its use began with the earliest published geologic literature. In geology, visualization is a long-standing technique. Computers have just made it more flexible. Techniques of computer visualization make it possible to update, correct, and improve traditional geologic maps. Color-coded visualizations of data are being used to review large data sets, to spot faulty data, and to model complex systems. The computer puts visual experimentation directly within the grasp of the researcher.

The increased use of color is occurring in many areas of the earth sciences. A few examples will show the diversity of research being done by groups that experiment with color-data representation:

- Remotely sensed images are being used as topographic base maps for traditional geologic mapping. Landsat and SPOT satellite images provide excellent coverage in the less frequently mapped areas of the world. The topographic data represented by the images can be analyzed quantitatively, and data can be added from other digital files as well.

- Seismic sections from multichannel seismic data, traditionally plotted in black and white, have started appearing with color coding. Color can be used to present signal velocity, and a pattern can be added to the color coding in order to indicate the quality of the signal. Color coding makes analysis of patterns and evaluation of the data easier.

- Gravity data collected by satellite altimeter readings use color to represent quantitative variations in the data. Shading of the colors highlights the prominent features and the regional fabric where the relief is too small to be defined adequately by the contours that are represented by different colors. Small-scale variations in the gravity field can be seen more easily by using color and color shading.

- High-resolution electrical images taken from boreholes are shaded with color in order to reveal detailed information for oceanic sediments when little core is recovered. The color images are understood more readily than the line graph of the conventional resistivity log.

The increased use of color computer visualization in the study of earth sciences is already having a dramatic effect on traditional methods of scientific communication. The American Geophysical Union rents the equipment necessary for video poster presentations at 
its meetings in order to make it possible to show animated color images. At the autumn 1989 meeting, over 20 poster presenters took advantage of this equipment. A full session of the section on oceans was entitled "Ocean Circulation Revealed by Video." The technological support is quite apparent to the audience because the presenters, equipped with a lapel microphone and a flashlight pointer, operateboth slide projectors and video machines. In one presentation, the moderator's help was required to keep the presenter from becoming tied up in his own electrical cords.

The increased use of color is already occurring in publications that are collected by earth science libraries as well. I examined the 157 core titles of the Lamont-Doherty Geological Observatory Library in the spring of 1990 . Of these, 26 , or 17 percent, had published papers that included color graphics within the first few months of the year. Some of these publications contained color graphics in every single issue. In its April issue. Geophysical Research Letters took another leap forward when an article by Michael Gurnis, entitled "Plate-Mantle Coupling and Continental Flooding," included a notice that a video containing additional graphic material could be ordered (Gurnis, 1990).

Is there an overall trend in color publishing? Scientific American continues its tradition of publishing shaded and multicolor graphics. However, the most important changes that are taking place use color to represent the original data. These changes are occurring in specialties that use remote-sensing data. Images from satellite data are used in specialties that you might suspect, like oceanography and atmospheric science, but these images are also found in papers on decidedly geologic topics. Color publishing is growing in the specialties of marine geology, seismology, and exploration geology. The many fields of earth science that involve work on various aspects of fluid dynamics are making extensive use of color in their complex models. Oceanographers are among the leaders in the use of animation in order to visualize the complex processes of ocean currents.

Let us contemplate the fact that the published literature is only the tip of the iceberg. High publication costs prevent even the researchers who use color-data sets from publishing their results completely in color. This presents an interesting dilemma. Researchers increasingly use color to help them analyze and manipulate their data (fig. 1), but often they must still publish in black and white. Is this a situation where the archive of research is increasingly in "inferior" black and white?

And let us consider the publishing process. In the review of the core titles that publish in color, a pattern emerged: the society journals are at the forefront of color publishing. Over one-half of the serial titles publishing in color are society publications that include the Society for Exploration Geophysicists, the American Association of Petroleum Geologists, and, far in the front, the American Geophysical Union.

Judy Holoviak, the head of American Geophysical Union ( $A G U$ ) publications. comments that $\mathrm{AGU}$ made a commitment to color many years ago because they saw it as essential to the representation of three-dimensional models. AGU has tried over the years to keep costs as low as possible, and it dramatically reduced its costs in July of 1990. AGU has experimented also with color sections and special color issues. Interestingly, recent issues that contain color have included clear color graphics printed on the same paper stock as the text.

The society journals that publish color illustrations commonly have page charges, including hefty charges for color. The normal text-page charge in the Journal of Geophysical Research is $\$ 140$ ( $\$ 72$ for camera-ready copy). The page charge for color is $\$ 700$ plus $\$ 250$ for art preparation. Note that the money to pay for color pages comes from the same place that the text-page charges come from: research grants. Grant allocations in the USA for publication costs have not changed yet to reflect the more expensive costs of color publication. As color publishing is only beginning to become a desirable feature of publishing. the new costs are being fit into existing budgets as needed.

Cost is not the only concern of researchers who experiment with the use of color-data representation. As mentioned previously, many researchers are concerned about the most effective use of color. In addition, the expense and unreliability of various color printers cause concern to researchers about producing working hard copy. And further, researchers using high-resolution satellite images also are concerned about the loss of resolution that comes with traditional publishing techniques.

The earth science libraries continue to have a difficult task coping with color. Patrons photocopy color-data images in black and white, much in the way that they photocopied maps in black and white. Volumes are sent on interlibrary loan more frequently than in other sciences. Some institutions make the effort to save their most important, heavily used volumes by making them into leadenly heavy, post-bound, mylar-encapsulated tomes. Geology is included within the dissertation microfilming that is handled by University Microfilms International, and yet the geology dissertations are almost impossible to use on black-and-white microfilm. Even the American Geophysical Union provides black-and-white microfilm of its publications to libraries whose staffs do not realize that the information contained within the illustrations is being lost.

The earth scientist continues to meet this challenge inventively. One researcher takes photocopies of maps he is interested in out to the field in the summer; when it rains, his student field assistants color them. A bright spot is the Canon Color Laser Copier, ' which has the ability to produce high-quality photocopies of color illustrations. This copier produces fairly reasonably priced color copies for $\$ 2-\$ 3$ and is becoming accessible in photocopy shops, but it is found rarely on academic campuses.

Earth science librarians have never been casual about the preservation issue in geology. The field has less microfilmed literature than any other science has, but the increased use of color in earth science publications only heightens the problem. Alarmingly, general science periodicals that are important to geology, such as Science and $\mathrm{Na}$ ture, are publishing data in color that is replaced quickly with blackand-white microforms in many libraries. This has been done because of a lack of realization that the DATA themselves are represented in color. The traditional preservation maxim is "preservation of the intellectual content." In libraries that have replaced these journals with black-and-white microforms, some of the intellectual content is being lost.

One of the things that may help the earth sciences is that earth science is not the only science exploring the representation of data in color - the molecular biologists, physicists, and even mathematicians are experimenting along these lines. By itself. the overall increased use of color may compel the preservationists to help solve the color problem.

Unfortunately, in a fairly wide ranging search of the library literature, no clear evidence existed that the need to preserve colorprinted materials was an issue. This was true until a seminar sponsored in 1988 by the Commission on Preservation and Access (USA) (1989), which was entitled, "Scholarly Resources in Art History." In fact, this is the only preservation document found that focused on images. Although color was not the emphasis of the seminar, its list of recommendations includes under short-term strategies: "Investigate state-of-the-art color microfilm technology, especially in Europe." and under long-term strategies: "Define and cxecute research for dark stability of color microfilm." In pursuit of these goals, the Commis-

\footnotetext{
Any use of trade. product, or firm names in this publication is for descriptive purpowes only and does not imply endorsement by the ILGS
} 
sion on Preservation and Access announced the establishment of a Joint Task Force funded by the Getty Foundation (USA) on disciplines that are dependent upon combined texts and images and the attendant need to preserve this literature.

Libraries have come full circle. Earth science libraries have been interested in color representation of data because of the enormous storehouse of literature that increasingly is becoming embrittled. Now the sprightly young literature must be made available to users and then ultimately preserved.

The earth sciences are at the front edge of a color computer revolution that is already having an impact on publishing and libraries. As color computer terminals become more common, I suspect that we will see more color-data representation and visualization of earth science problems in an increasingly larger number of disciplines of the earth sciences. The impact is being felt already, and as it should be, the researchers are taking the lead. Now it is up to the many support functions of science - the conference organizers, the publishers, and the librarians - to ensure that the latest color-data representation is as well communicated, distributed, and ultimately preserved as earth science information has been in the past.

\section{References}

Carter, R.C., 1982, Visual search with color: Journal of Experimental Pyschology, v. 8, no. 1, p. 127-136.

Commission on Preservation and Access, 1989, Scholarly resources in art history: Issues in preservation: Spring Hill, Wayzata, Minnesota, USA, September 29-October 1, 1988, Report: Washington, D.C., 43 p.
Gurnis, M., 1990, Plate-mantle coupling and continental flooding: Geophysical Research Letters, v. 17, no. 5, p. 623-626.

Klimley, Susan, 1982, Geological maps in books and serials: A hidden preservation problem: Geoscience Information Society Proceedings, v. 13 , p. $136-143$

McCormick, B.H., Defanti, T.A., and Brown, M.D., eds., 1987. Visualization in scientific computing: SIGGRAPH Computer Graphics Newsletter, v. 21 , no. 6 , various pagings.

Phillips, R.J., and Noyes, L., 1980, A comparison of colour and visual texture as codes for use as area symbols on thematic maps: Ergonomics, v. 23 , no. 12 , p. $1117-1128$.

Walker, David, 1845 , On the newer coal formation of the eastern part of Nova Scotia: Quarterly Journal of the Geological Society of London, v. 1 , p. 322 .

Weert, C.M.M. de, 1988, The use of color in visual displays, in Veer, G.C. van der, and Mulder, G., eds., Human-computer interaction: Psychonomic aspects: Berlin, Springer-Verlag, p. 85-100.

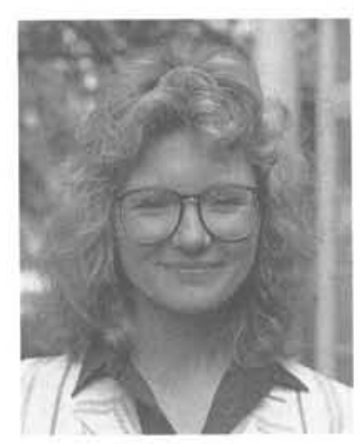

Susan Klimley is a Geological Sciences Librarian at the LamontDoherty Geological Observatory of Columbia University, Palisades, New York. Her research interests focus on earth science information including collection development, examination of the impact of new computer applications, and the special preservation needs of geologic literature. 